\title{
Colour Stability of Composite- A Review
}

Arpan Sanjay Jaiswal ${ }^{1}$, Pradnya Prashant Nikhade², Manoj Chandak ${ }^{3}$, Samrudhi Khatod ${ }^{4}$, Chanchal Rathi ${ }^{5}$, Juhi Jaiswal ${ }^{6}$

${ }^{1}$ Department of Conservative Dentistry and Endodontics, Sharad Pawar Dental College, Datta Meghe Institute of

Medical Sciences, Sawangi Meghe, Wardha, Maharashtra, India. ${ }^{2}$ Department of Conservative Dentistry and

Endodontics, Sharad Pawar Dental College, Datta Meghe Institute of Medical Sciences, Sawangi Meghe, Wardha,

Maharashtra, India. ${ }^{3}$ Department of Conservative Dentistry and Endodontics, Sharad Pawar Dental College, Datta

Meghe Institute of Medical Sciences, Sawangi Meghe, Wardha, Maharashtra, India. ${ }^{4}$ Department of Conservative

Dentistry and Endodontics, Sharad Pawar Dental College, Datta Meghe Institute of Medical Sciences, Sawangi Meghe, Wardha, Maharashtra, India. 5 Department of Conservative Dentistry and Endodontics, Sharad Pawar Dental College, Datta Meghe Institute of Medical Sciences, Sawangi Meghe, Wardha, Maharashtra, India. ${ }^{6}$ Department of Conservative Dentistry and Endodontics, Sharad Pawar Dental College, Datta Meghe Institute of Medical Sciences, Sawangi Meghe,

Wardha, Maharashtra, India.

\section{ABSTRACT}

\section{BACKGROUND}

Current innovations in restorative dentistry include nanofilled composite resin materials for direct and indirect restorations. Moreover, the advances in adhesive dentistry have provided autopolymerising, dual-polymerizing and light polymerizing resin-based adhesives for ceramic restoration bonding. In addition, resin cements have been combined with self-adhesive components for adhesive procedures. Composite failure has been a great challenge for dental clinician all over the world, making it difficult for the dentist to satisfy patients. Major problems seen include polymerization, shrinkage and colour instability. There being no perfect method for this restorative material to overcome the problems, clinicians must keep in mind as to what material and technique should be used in a patient depending upon the case. The success of composite restorations is due to their colour stability over time. Accurate shade matching of tooth coloured restoration with the adjacent dentition is essential not only at the time of fabrication but also for the lifetime durability. Discolouration of composite resins can be caused by internal or external factors. Internally induced discolouration is permanent and is related to polymer quality, filler type, and amount, as well as the synergist added to the photo initiator system. Alteration of matrix or filler components of resin composites and incomplete polymerization constitute intrinsic factors leading to discolouration. It is reported that saliva, food components, and beverages may affect the aesthetics and integrity of dental composites. This is a factual truth for dental porcelain but in contradiction, colour instability in porcelain restoration is a common dilemma nowadays, especially when they are exposed to routinely consumable beverages. We have reviewed different factors responsible for colour stability of composite restoration, and different steps that can be taken to avoid discolouration and polymerization shrinkage.

\section{KEY WORDS}

Composite, Polymerization, Colour Stability
Corresponding Author:

Dr. Arpan Sanjay Jaiswal Postgraduate Student,

Department of Conservative Dentistry and Endodontics, Sharad Pawar Dental College, Wardha, Maharashtra, India.

E-mail: kanhaa.jaiswal@gmail.com

DOI: $10.14260 /$ jemds/2020/419

Financial or Other Competing Interests: None.

How to Cite This Article:

Jaiswal AS, Nikhade PP, Chandak M, et al. Colour stability of composite- a review. J. Evolution Med. Dent. Sci. 2020;9(26): 1928-1934, DOI:
Submission 31-12-2019,

Peer Review 30-05-2020,

Acceptance 06-06-2020,

Published 29-06-2020. 


\section{BACKGROUND}

Restoration is one of the vital specialties of dentistry. In spite of improvements in materials used for restorative dentistry, there is no material that is ideal for this dental application.(1) In the current periods, tolerable hue match for "posterior restorations" is also an imperative thought in aesthetic dentistry.(2) Surface irregularity, surface lustre, and colour are the most important aesthetic essentials of a restoration. (3) It is testified that saliva, food constituents, and beverages may affect the aesthetics and reliability of dental composites leading to its dilapidation in the oral environment. ${ }^{(4)}$ Change in colour of resin-composite can be due to the external factors or inner factors. Within prompted stains are everlasting which are in association with polymer excellence, fillers type, amount, plus also the auxiliary synergist to the 'photoinitiator method'. In light-activated resin- composite, when curing is inadequate, yellowish change in is seen because of remaining unconverted camphor quinone. Moreover, additional constituent of the light activated system that is 'tertiary aromatic' or 'aliphatic amines' have a tendency to make yellowish or brownish stain with stimulus of 'light' or 'heat'. The resin's empathy for external stains is controlled with adaptation percentage and physical-chemical physiognomies, and aquatic absorption rate being of specific importance. Inside mouth cavity, for the reason that of apparent deprivation or a slim diffusion and adsorption of staining agents at the shallow layer of the resin-composite, the superficial or sub-surface staining of resin-composite is seen. Furthermore, outwardly brought stains is associated to surface coarseness, surface veracity, plus with refining system.

Conferring to "Asmussem E"[5] and "Dietschi D et al"[6] at hand are 3 different sorts of resin-composite discolourations [3]: 1) External dis-colouration: This is due to the growth of 'plaque and external pigments; 2) Internal discolouration: This is due to the maturing of material; 3 ) Modification of the superficial colour because of apparent deprivation or slight infiltration with reaction of the tinting materials on the inner side of apparent resin -composite film. Colour stability can be defined as the capability of the restoration to hold the original colour. Oral cavity is having a active environment. There is existence of microbes, saliva and numerous ingestions of coloured food products which might affect the colour stability of the restoration. Moreover, physical and mechanical properties are given more attention than the property of colour solidity of resin- composites' which will hamper colour of the resin. Colour perception vary with person to person being a psychological issue and it can be portrayed differently by different person. So, to avoid this problem, colour assessing equipment made engaged and the records were collected in "CIE L*a*b* system" [7]

"CIE L*a*b* system" practices 3-D 'colourimetric' measurement: ' $\mathrm{L}^{*}$ values' accord with intensity of the colour," $\mathrm{a}^{*}$ 'values' to the red and green content, and $\mathrm{b}^{*}$ values to yellow-blue content". The colour variations $(\Delta \mathrm{E})$ is calibrated with the $\mathrm{L}^{*}, \mathrm{a}^{*}$, and $\mathrm{b}^{*}$ values for each specimen, conferring to the subsequent formulation, it will controls the 3-D colour space: $\Delta$ Elab $^{*}=\left[\left(\Delta \mathrm{L}^{*}\right) 2+\left(\Delta \mathrm{a}^{*}\right) 2+\left(\Delta \mathrm{b}^{*}\right) 2\right] 1 / 2$, while brilliance values (DL*) were reached using $\Delta \mathrm{L}^{*}=\mathrm{L}^{*}(\mathrm{tx})-$ $\mathrm{L}^{*}(\mathrm{t} 0)$, in which ' $(\mathrm{tx})^{\prime}$ ' will represent dipping time and (t0) the baseline. (8) An observable colour difference which is $\Delta \mathrm{E}^{*}>1.0$ will be denoted to as tolerable up to the value $\Delta \mathrm{E}^{*}=3.7$, in individual visual grits made in vitro under ideal light situations.(9) In this review there is detailed information of different factors influencing the colour steadiness of the resin-composite filling.

\section{Factors Responsible for Colour Stability of Composite Restoration}

Various factors are associated which affects the colour constancy of the "resin-composite". Colour stability is association with the resin-matrix, dimension of its filler particles, "polymerization" degree and the colouring agents. (10-12) Change in colour of teeth-coloured, resin might be due to interior or exterior elements. Intrinsic aspect includes physicochemical staining responses in the resin-composite matrix, in superficial and deeper layers of the resin composition, activated by ultraviolet (UV) irradiation, thermal energy, or humidity. Chemical change in colour of resin material has been ascribed to variation or oxidation in the amine-accelerator, oxidation in the configuration of the polymer matrix, and oxidation of the un-reacted pendant "meth-acrylate groups".(13)

\section{INTRINSIC FACTORS}

\section{Matrix}

According to studies urethane di-methacrylate was more colour stable than di-methacrylate matrix. Urethane dimethacrylate had lower water absorption and was found low viscous as compared to di-methacrylate only. (14)

\section{Fillers}

"Ormocer" along its rigid matrix containing three-D linked "organic \& in-organic ormocers" had more wear resistance as well as can resist discolouration as compared to mircofilled or micro hybrid composite. Excessive water absorption leads to expansion and also causes plasticizing of the resin-matrix component, hydrolysing the saline and leading to micro-crack development leading to discolouration.(15)

\section{Photo Initiators}

Discolouration can be attributed to the efficacy of polymerization, more the degree of conversion, lesser the availability of residual monomer to get discoloured.(15) according to studies LED unit caused least colour change when was compared with quartz - tungsten- halogen units and jet lite. When compared led with halogen lamp they used higher power density LED UNIT $\left(790 \mathrm{~mW} / \mathrm{cm}^{2}\right)$ which according to Bala et al. high degree of monomer conversion.(16)

\section{EXTRINSIC FACTORS}

\section{Types of Food Colourant}

Numerous types of food with colours agents have impending effect on the change in colour of the resin material which 
include coffee and tea, aerated and non- aerated beverages and disinfection agents used in mouth washes have tendency to discolour.(17,18) Chlorhexidine a most commonly used broad - spectrum topical antibacterial agent for treatment of diseases which occur in oral cavity. It is seen that it causes discolouration of the restoration particularly with combination of the dietary intake. Intake of beverages including coffee or tea may lead to change in aesthetic and physical assets of the "resin-composite", there-by degrading its value of the composite. Sparkling drinks are acidic and can be disadvantageous to the assets of filling "resincomposite".(19,20)

\begin{tabular}{|c|c|}
\hline Extrinsic & Intrinsic \\
\hline Food and drinks(beverages) & Pulpal necrosis \\
\hline Tobacco use(all forms of tobacco) & $\begin{array}{l}\text { Obliteration of chamber } \\
\text { (ex. Traumatic injury to teeth) }\end{array}$ \\
\hline $\begin{array}{l}\text { Poor oral condition (stains and } \\
\text { calculus) }\end{array}$ & $\begin{array}{c}\text { Dental materials } \\
\text { (ex. Extensive amalgam restorations) }\end{array}$ \\
\hline Topical medications (CHX) & $\begin{array}{l}\text { heredity disorders } \\
\text { (ex. "Amelogenesis imperfect") }\end{array}$ \\
\hline $\begin{array}{l}\text { Metallic compounds Deposition of } \\
\text { FE, Mn, Hg) }\end{array}$ & Metabolic disorders (ex. "Alkaptonuria") \\
\hline \multirow[t]{2}{*}{$\begin{array}{c}\text { Enamel wear-off } \\
\text { ("Abrasion, attrition, erosion") }\end{array}$} & Antibiotic drugs (ex., "tetracycline") \\
\hline & $\begin{array}{c}\text { Dentinal Fluorosis (ex. Excessive } \\
\text { fluoride uptake) }\end{array}$ \\
\hline $\begin{array}{r}\text { Table 1. Co } \\
\text { Cause }\end{array}$ & $\begin{array}{l}\text { Extrinsic and Intrinsic } \\
\text { ooth Discolouration }\end{array}$ \\
\hline
\end{tabular}

\section{STEPS TO AVOID DISCOLOURATION}

\section{Technique of Placement of Composite Restoration}

Composite-resin helps for nominally aggressive or to make cavity when supposing the renewal of cavitated or missing tissues that allows for new notion known as "Bio aesthetics". It is normally quite well known that every resincomposites contract while polymerization guiding to disappointment. This contraction leads to many encounters while placing and photo-curing the composite.(21-26)

Three important factors correspond to minimize "shrinkage" pressure: usage of a less material, a minor cavity structure aspect, and less communication with the contralateral cavity walls while" polymerization". The notably, known "incremental technique" declines shrinkage stress because of diminished polymerization resin amount. Every part is recompensed by the other, with the significance of polymerization contraction is least detrimental as only the amount reduction of the ending deposit might harm the bonded surfaces.(27)

\section{INCREMENTAL TECHNIQUES FOR DIRECT COMPOSITE RESTORATION}

While placement of resin-composites in molar and premolar, using minute 'increments' is suggested by a lot of authors for placement and polymerization so that contraction stress can be lowered. Seeing anterior resin-composite filling, however the assignment of augmentations leads to reduced polymerization contraction tension, faults in layering systems will lead to outcome in filling which are too "translucent or opaque". So as-to safeguard aesthetically courteous consequences, layering ideas notion be simple, methodized, and replicable.

\section{Horizontal Layering Technique}

This horizontal engagement method employs "resincomposite" increment, all less than $2.0 \mathrm{~mm}$ dense [Fig 1]. The method stated to have increased the C-factor, and thereupon intensifications of the shrinkage stress in between the contralateral cavity walls is noticed.[28,29,30]

\section{Oblique Layering Technique}

The oblique method is achieved by putting a chain of "wedgeshaped" "resin-composite" augmentations. Every layer is light activated twice, majorly via the cavity walls and later commencing the occlusal surface, directing the trajectories of polymerization headed to the bonding surface [Figure II] This method diminishes the "C-factor" and averts the alteration of cavity walls:[27-30]

\section{Vertical Layering Technique}

Put less parts of resin composite in 'vertical' manner beginning from 1st wall, which can be either., 'buccal' or 'lingual' and then taken to other side. Begin light curing from back of the wall, that is, if 'buccal' part is put on the "lingual wall", it is photo activated from external surface of the "lingual wall". This led to reduction in slit at 'gingival wall which is made because of "polymerization contraction", hence forward leading to "post-operative sensitivity" and "secondary caries" [Figure III].

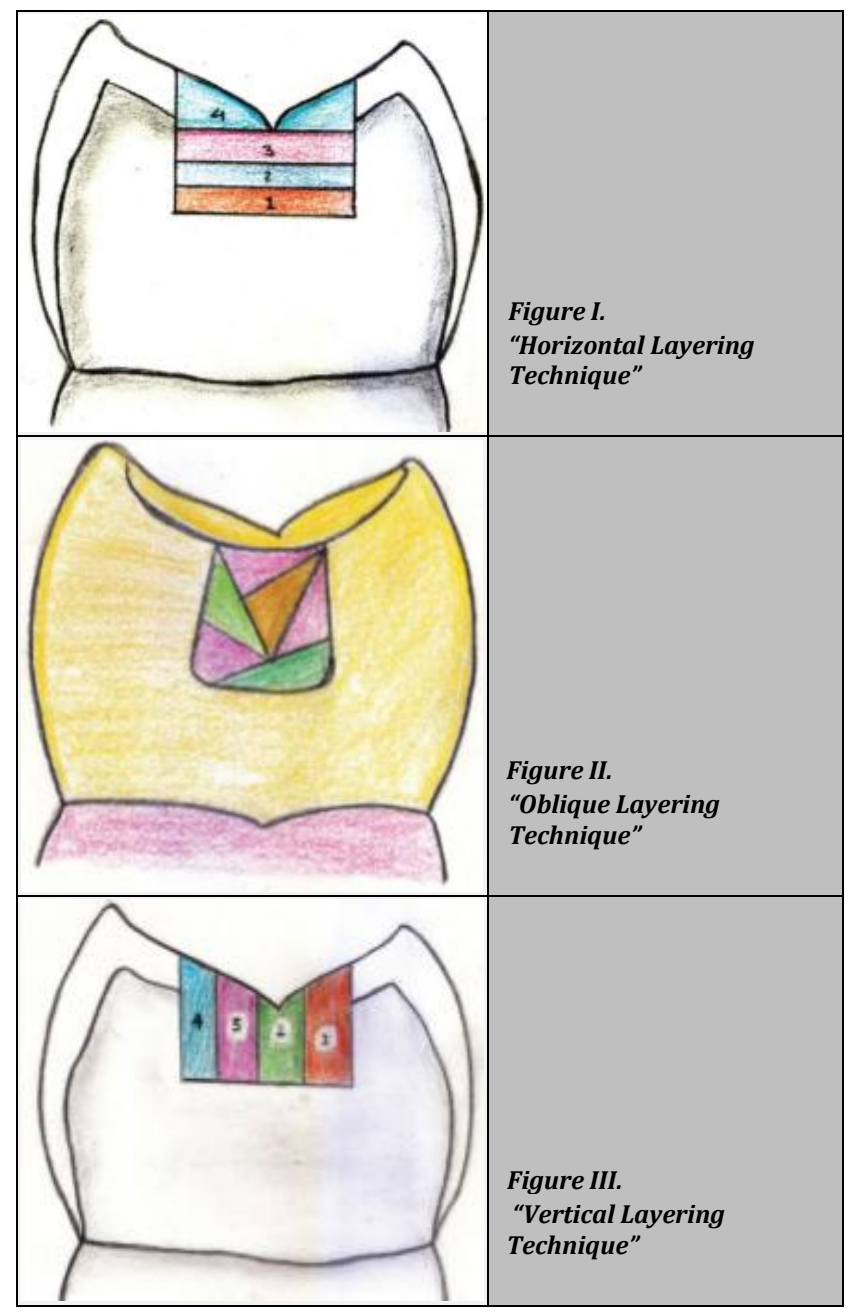




\section{Stratified Layering Technique}

This system was connived and adapted to the growth of purposeful and anatomical restoration putting on the "esthetic" resin filling resources which comprise colours of' dentin and enamel' and including different translucent and intense colours:[31,32,33] it is a method made to carve several grades of chroma existing inside a tooth. Which include putting dentinal "shades" of resin-filling with a advanced 'chroma' in the middle of the prepared cavity and putting a "lower chroma" resin near to the cuspal walls. The "stratified layering" method is achieved by putting dentinal coatings of resin-composite "shades" or "chromas" that are of 2 or 3 degree advanced than the elected normal shades or "chroma". Precise differences in dentinal colour can be attained by altering the width of each "chroma layer" in exact areas of the restorations. The "enamel layer" is positioned succeeding the outlines entrenched by the dentinal layers and contrasts in width reliant on the acceptable consequence. The "enamel layer" can be altered by putting different "shades" of "opalescent" or "intensive enamels" on different places of the fillings. [31,32]

\section{Centripetal Build-Up Technique}

This method provides a lot of upper hand when paced posteriorly. This method engages fine' metal matrix band's and wooden wedges [Figure IV] moreover, current readings doesn't designate any impairment of "metal matrix bands" in cervical breach development. ${ }^{[34]}$

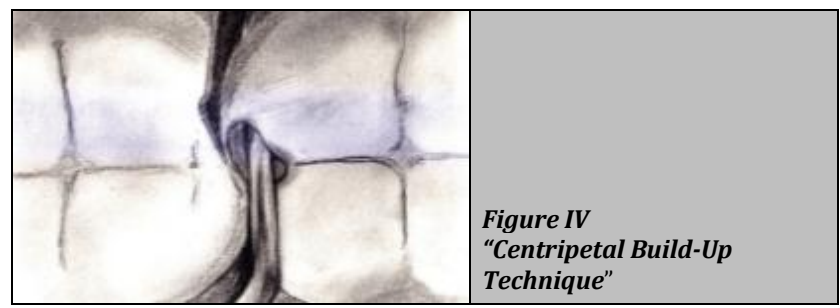

Added importance for this method is appointed by the "centripetal build-up steps" $1^{\text {st }}$ by making an exact slim "proximal layer" [Figure 4]; the interior "curing" of this layer is contrived which can reinforce the "resin-composite" and reduce cervical space.[35,36] Moreover, there is space seen, very following layer filling the 'gingival floor' will fill the gap. Construction of 'occlusal surface ring' is an alternative important accumulation of the given method. By putting unceasing increment to "cusp slopes", an "occlusal" orientation base is designed, evading over-filling and decreasing the very necessity for 'rotary burs'. This finishingpolishing procedure are seem to harmful for exterior surface of the composite-resin.[37] 'Centripetal build-up technique' being conventional with safeguarding of good teeth structure, is time-consuming and it is easy to execute.

\section{Split-Increment Horizontal Layering Technique}

When 'horizontal technique' is put to use, all the resincomposite increment which contact cavity walls leads to maximum $C$ factor $[28,29,30]$ THERE has been concern relating to put 'increments' against the opposite walls at the same time, this will lead to shrinkage stress which will bend the cusp onward each other giving deformed result. It might lead to post-operative 'sensitivity' and might be damaging for the teeth along with 'marginal integrity' [38] for the given method, every 'horizontal increment' was fragmented, beforehand polymerizing, into "four triangle-shaped portions" [Figure 7], with every serving sited alongside individual 'cavity wall' and single 'diagonal cut' was occupied entirely with "dentinal shade" composite-resin and light-cured. At this very point, another "diagonal cut" was packed and light -cured, one part a time. Similar system is used till "dentin \& enamel" junction and after' enamel shade composite' trailed by 'translucent shade' are put and formed to start 'occlusal morphology'. This will uniformly decrease the "C-factor" ratio from five, which is the maximum and the greatly disapproving, to the subsequent most promising "C-factor ratio" of 0.5 .

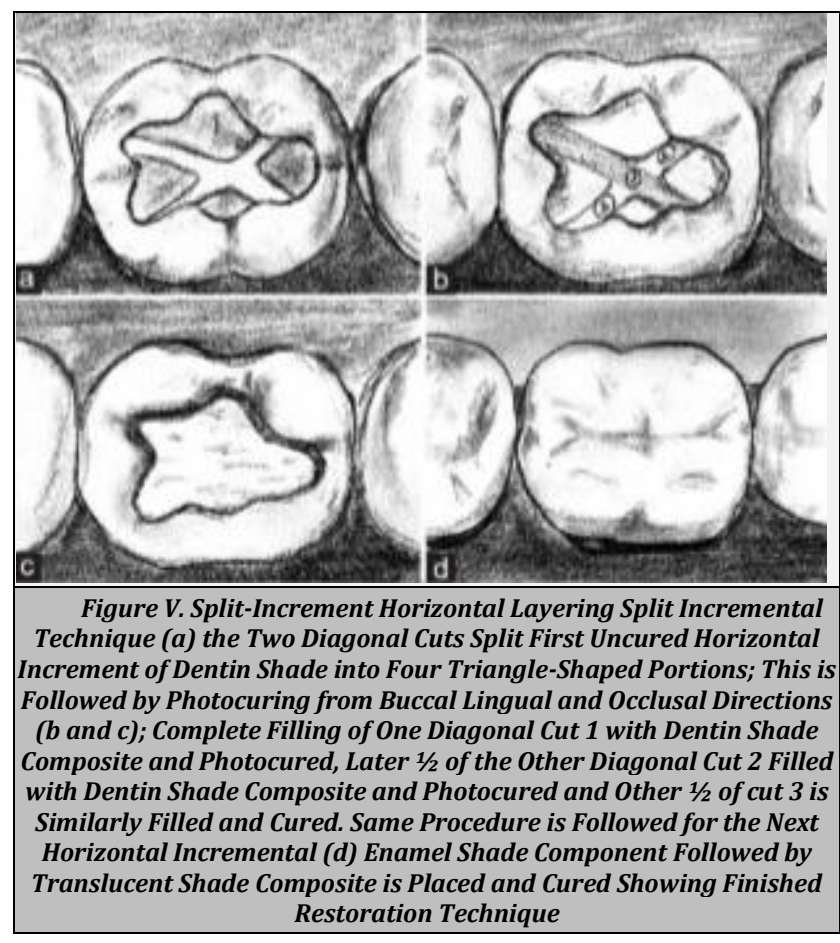

\section{Successive Cusp Build-Up Technique}

Here, separate "cusps" filled one by one up to the equal of the "occlusal enamel". Small slanted additions are smeared to each curve of the prepared cavity [Figure VI] in-turn and handling is set aside to a lowest, to dodge foldaway spaces into the material. This process at first is time wasting, and might critically decrease 'finishing' time by exact consideration to progressive re-construction of usual morphology.[39]

\section{Separate Dentine and Enamel Build-Up Using an Index} Using this disparity will re-establish decayed teeth with unbroken occlusal surface. After "rubber-dam" engagement, a pre-operative "impression" is to be taken of the occlusalsurface. When layered "dentine" filling is done, the impression material is used to help exact alteration of the concluding "enamel" increments. By cautiously controlling of the quantity of composite used, this system may totally reject the concluding phase [Figure VII].[39] 

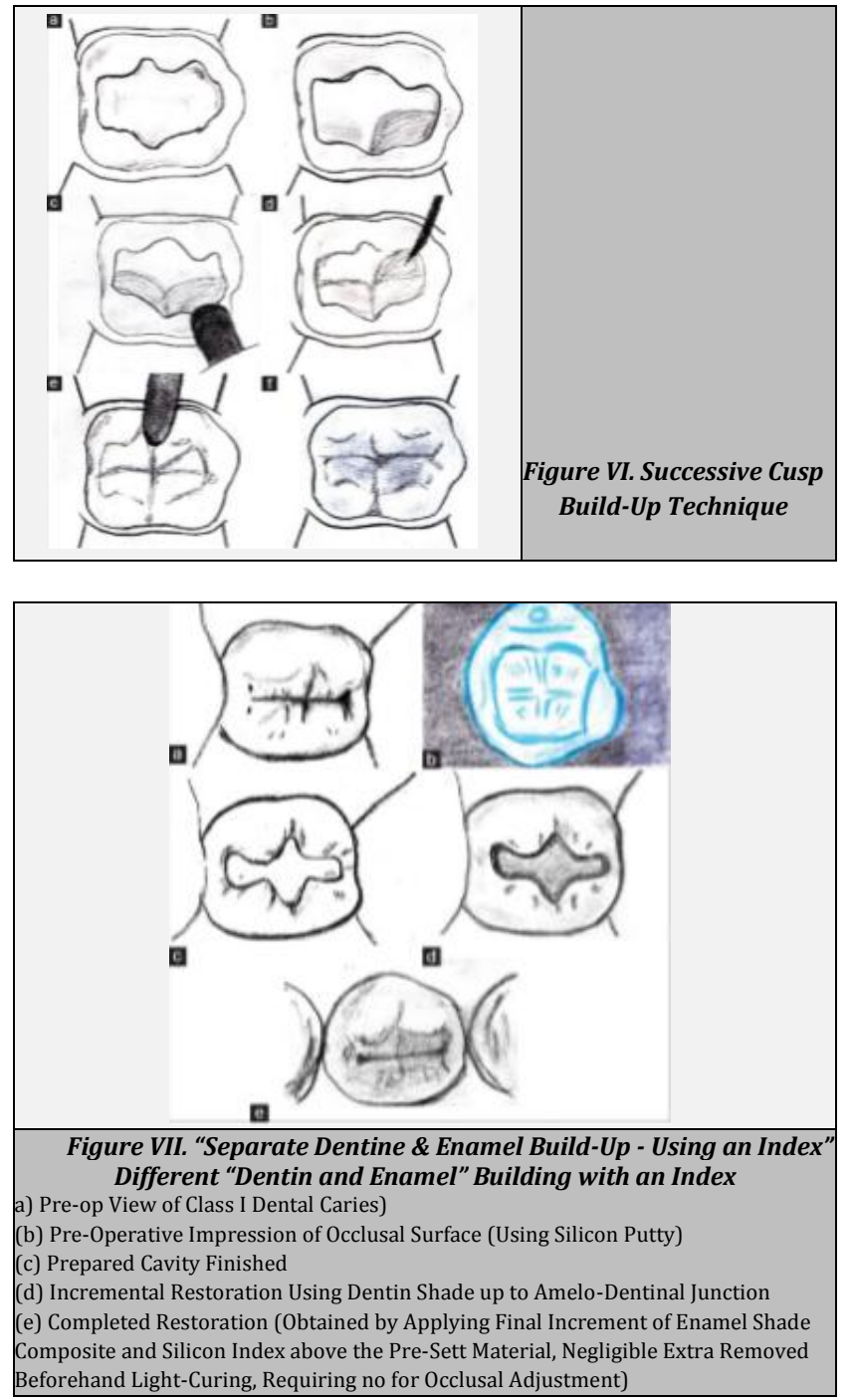

\section{Three-Site Technique}

This system which is related to the usage of a pure "matrix" and brooding wedges. Firstly, the "light-curing" is fixed through the 'matrix and wedges' in the effort to guide the "polymerization" trajectories on the way to the gingival boundary hence stopping any space development. Then, "wedge shaped" "resin- composite" additions are positioned to further impede alteration of cavity walls and decrease the "C factor" [Figure VIII]. This system is related with "polymerization" first through the cavity walls and then from the occlusal surface in command to unswerving the trajectories of "polymerization" in the direction of the adhesive surface.[28]

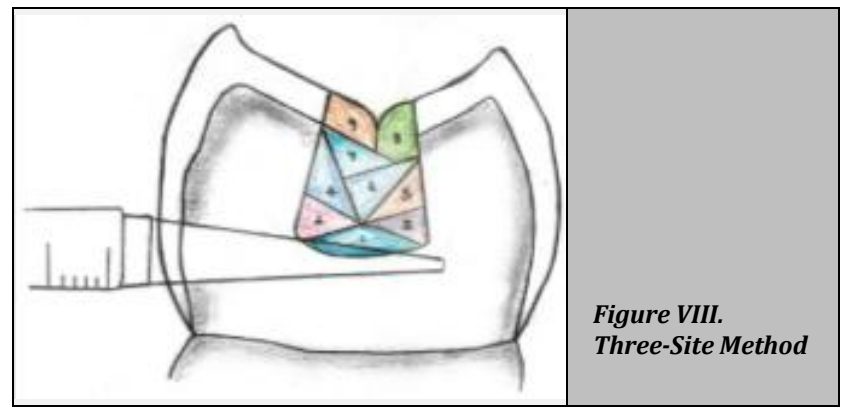

\section{Bulk Technique}

This system is suggested by some writers to decrease pressure at the 'cavosurface margins'.[27] While" anterior composite" filling are omnipresent, using innovative several layering systems by means of selection of "shades", opacities, and translucencies rests the domain of fairly few dentalpractitioner. This succeeding simple dual shade and more complex multi-layered engagement sequences are obtainable as systematic guidelines for all practitioners yearning to form added natural seeing direct anterior "resin-composite" filling.

\section{Dual-Shade Layering Technique}

Rudimentary dentist is suggested to create self-assurance in layering systems by commencement with binary material "shades" as this easy system is stated to convey a tolerable colour competition in a big number of scientific situations. Subsequent "etching and adhesive submission", 'opaque dentine' material is functional, formed, and light cured. Most dentine filling materials are in the shade group-A and assortment of the corrected chroma is a crucial to triumph. "Palatal, proximal, and labial enamel" augmentations are then layered, free hand over the opacious dominant core at roughly fifty percent width of remaining enamel.[40]

\section{Polychromatic Layering Technique}

Whenever aesthetic loads are great, the extensively acknowledged stratification system projected by "Lorenzo Vanini" is suggested.[41] The essential code of 'polychromatic' layering system is to use diverse "resin-composite" shades to duplicate the coatings seen in usual teeth which can be labelled in coats as 'palatal enamel layer', 'dentine layer', distinctive types, opalescent, classifications, and intensives:[42]

\section{CONCLUSIONS}

Direct resin-composite fillings have become an essential portion of today's dental practice. With growing technical progression, there has been up-gradation in resincomposites, which will advance efficacy and speediness of their assignment, with the intension of extended-lasting and correctly shaped filling. A careful functioning system alongside suitable case assortment oversees the accomplishment of resin-composite filling.

\section{REFERENCES}

[1] Panchbhai A. Nano composites: past, present, and future of dentistry. In: Asiri AM, Inamuddin, Mohammad A, eds. Applications of nanocomposite materials in dentistry. $1^{\text {st }}$ edn. Woodhead Publishing 2018:181-90.

[2] Malhotra N, Shenoy R, Mayya S, et al. Effect of three indigenous food stains on resin based, microhybrid and nano composites. J Esthet Restor Dent 2011;23(4):250-7. 
[3] Yap AU, Sau CW, Lye KW. Effects of finishing/polishing time on surface characteristics of tooth-coloured restoratives. J Oral Rehabil 1998;25(6):456-61.

[4] Goldstein RE, Garber DA, Schwartz CG, et al. Patient maintenance of aesthetic restorations. J Am Dent Assoc 1992;123(1):61-7.

[5] Dietschi D, Campanile G, Holz J, et al. Comparison of the colour stability of ten new-generation composites: an in vitro study. Dent Mater 1994;10(6):353-62.

[6] Gaintantzopoulou M, Kakaboura A, Vougiouklakis G. Colour stability of tooth-coloured restorative materials. Eur J Prosthodont Restor Dent 2005;13(2):51-6.

[7] Gupta R, Parkash H, Shah N, et al. A spectrophotometric evaluation of colour changes of various tooth coloured veneering materials after exposure to commonly consumed beverages. J Indian Prosthodont Soc 2005;5(2):72-8.

[8] Powers JM, Sakaguchi RL. Craig's restorative dental materials. St Louis, MO: Mosby Elsevier 2006.

[9] Domingos PA, Garcia PP, Oliveira AL, et al. Composite resin colour stability: influence of light sources and immersion media. J Appl Oral Sci 2011;19(3):204-11.

[10] Inokoshi S, Burrow MF, Kataumi M, et al. Opacity and colour changes of tooth-coloured restorative materials. Oper Dent 1996;21(2):73-80.

[11] Yannikakis SA, Zissis AJ, Polyzois GL, et al. Colour stability of provisional resin restorative materials. J Prosthet Dent 1998;80(5):533-9.

[12] Ergücü Z, Türkün LS, Aladag A. Colour stability of nanocomposites polished with one-step systems. Oper Dent 2008;33(4):413-20.

[13] Catelan A, Briso ALF, Sundfeld RH, et al. Colour stability of sealed composite resin restorative materials after ultraviolet artificial aging and immersion in staining solutions. J Prosthet Dent 2011;105(4):236-41.

[14] Bagheri R, Burrow MF, Tyas M. Influence of foodsimulating solutions and surface finish on susceptibility to staining of aesthetic restorative materials. J Dent 2005;33(5):389-98.

[15] Samra AP, Pereira SK, Delgado LC, et al. Colour stability evaluation of aesthetic restorative materials. Braz Oral Res 2008;22(3):205-10.

[16] Bala 0, Olmez A, Kalayci S. Effect of LED and halogen light curing on polymerization of resin-based composites. J Oral Rehabil 2005;32(2):134-40.

[17] Nordbö H, Attramadal A, Eriksen HM. Iron discolouration of acrylic resin exposed to chlorhexidine or tannic acid: a model study. J Prosthet Dent 1983;49(1):126-9.

[18] Raptis CN, Powers JM, Fan PL, et al. Staining of composite resins by cigarette smoke. J Oral Rehabil 1982;9(4):36771.

[19] Powers JM, Fan PL, Raptis CN. Colour stability of new composite restorative materials under accelerated aging. J Dent Res 1980;59(12):2071-4.

[20] Fay RM, Servos T, Powers JM. Colour of restorative materials after staining and bleaching. Oper Dent 1999;24(5):292-6.

[21] Zachrisson BU, Mjör IA. Remodeling of teeth by grinding. Am J Orthod 1975;68(5):545-53.

[22] Heymann HO. Conservative concepts for achieving anterior aesthetics. J Calif Dent Assoc 1997;25(6):43743.
[23] Leonard RH, Bentley C, Eagle JC, et al. Nightguard vital bleaching: a long-term study on efficacy, shade retention. Side effects, and patients' perceptions. J Esthet Restor Dent 2001;13(6):357-69.

[24] Ritter AV, Leonard RH, St. Georges AJ, et al. Safety and stability of nightguard vital bleaching: 9 to 12 years posttreatment. J Esthet Restor Dent 2002;14(5):275-85.

[25] Sundfeld RH, Croll TP, Briso AL, et al. Considerations about enamel microabrasion after 18 years. Am J Dent 2007;20(2):67-72.

[26] Donly KJ, Jensen ME. Posterior composite polymerization shrinkage in primary teeth: an in vitro comparison of three techniques. Pediatr Dent 1986;8(3):209-12.

[27] Giachetti L, Scaminaci Russo D, Bambi C, et al. A review of polymerization shrinkage stress: current techniques for posterior direct resin restorations. J Contemp Dent Pract 2006;7(4):79-88.

[28] Spreafico RC, Gagliani M. Composite resin restorations on posterior teeth. In: Roulet JF, Degrange M, eds. Adhesion: the silent revolution in dentistry. Chicago: Quintessence Publishing 2000:253-76.

[29] Lutz F, Krejci I, Barbakow F. Quality and durability of marginal adaptation in bonded composite restorations. Dent Mater 1991;7(2):107-13.

[30] Tjan AH, Bergh BH, Lidner C. Effect of various incremental techniques on the marginal adaptation of class II composite resin restorations. J Prosthet Dent 1992;67(1):62-6.

[31] Vanini L. Light and colour in anterior composite restorations. Pract Periodontics Aesthet Dent 1996;8(7):673-82.

[32] Ritter AV. Posterior resin-based composite restorations: clinical recommendations for optimal success. J Esthet Restor Dent 2001;13(2):88-99.

[33] Klaff D. Blending incremental and stratified layering techniques to produce an aesthetic posterior composite resin restoration with a predictable prognosis. J Esthet Restor Dent 2001;13(2):101-13.

[34] Coli P, Brännström M. The marginal adaptation of four different bonding agents in class II composite resin restorations applied in bulk or in two increments. Quintessence Int 1993;24(8):583-91.

[35] Von Beetzen M, Li J, Nicander I, et al. Microhardness and porosity of class 2 light-cured composite restorations cured with a transparent cone attached to the lightcuring wand. Oper Dent 1993;18(3):103-9.

[36] Ericson D, Dérand T. Reduction of cervical gaps in class II composite resin restorations. J Prosthet Dent 1991;65(1):33-7.

[37] Dickinson GL, Leinfelder KF, Mazer RB, et al. Effect of surface penetrating sealant on wear rate of posterior composite resins. J Am Dent Assoc 1990;121(2):251-5.

[38] Opdam NJ, Roeters FJ, Feilzer AJ, et al. Marginal integrity and postoperative sensitivity in Class 2 resin composite restorations in vivo. J Dent 1998;26(7):555-62.

[39] Mackenzie L, Shortall ACC, Burke FJT. Direct posterior composites: a practical guide. Dent update 2009;36(2):71-2.

[40] Manauat J, Salat A. An atlas of composite resin stratification. London: Quintessence Publishing Co Ltd 2013. 
[41] Chiche GJ, Pinault A. aesthetics of anterior fixed prosthodontics. $1^{\text {st }}$ edn. London: Quintessence Publishing 1994. ISBN 978-0-86715-258-6.
[42] Mackenzie L, Parmar D, Shortall ACC, et al. Direct anterior composites: a practical guide. Dent Update 2013;40(4):297-9. 